\title{
Evaluation of different platforms for the detection of anti-SARS coronavirus-2 antibodies, Thailand
}

\author{
Hatairat Lerdsamran ${ }^{1}$, Anek Mungaomklang ${ }^{2}$, Sopon lamsirithaworn³, Jarunee Prasertsopon?', \\ Kriengkrai Prasert ${ }^{4}$, Poj Intalapaporn ${ }^{5}$, Nirada Siriyakorn ${ }^{5}$, Witthawat Wiriyarat ${ }^{6}$, Nattakan Thinpan ${ }^{1}$, \\ Suteema Sawadpongpan', Somrak Sirikhetkon², Noparat Mongkalangoon ${ }^{3}$, Suwanna Petto ${ }^{2}$ and \\ Pilaipan Puthavathana ${ }^{1 *}$
}

\begin{abstract}
Background: Antibodies against severe acute respiratory syndrome coronavirus 2 (SARS-CoV-2) help determine previous infection in individuals, regardless of whether they are asymptomatic or symptomatic. The detection of antibodies serves several purposes, including supporting other assays for disease diagnosis, conducting seroepidemiological studies, and evaluating vaccines. Many platforms of immunological methods for anti-SARS-CoV-2 antibody detection and their performance require validation.

Methods: This study evaluated the test performance of three autoanalyzer-based assays (Architect lgG, Vitros IgG, and Vitros total lg) and one manual ELISA (Wantai total Ig) against a microneutralization (microNT) assay on the detection of SARS-CoV-2 antibodies. Furthermore, an indirect immunofluorescence assay verified the discordant results between the microNT and commercial assays. The test sensitivity, specificity, positive predictive value, and negative predictive value were determined based on four groups of 1005 serum samples: 102 COVID-19 prepandemic sera, 45 anti-SARS-CoV-2 positive sera, 366 sera of people at risk, and 492 sera of citizens returning from countries with a high prevalence of infection.
\end{abstract}

Results: The analyses as a whole showed that the performance of these commercial assays was comparable. Each group was also analysed separately to gain further insight into test performance. The Architect did not detect two positive sera of people at risk (prevalence of infection $0.55 \%$ ). The other methods correctly identified these two positive sera but yielded varying false-positive results. The group of returning travellers with an infection rate of 28.3\% (139 of 492) better differentiated the test performance of individual assays.

Conclusions: High-throughput Architect and Vitros autoanalyzers appear appropriate for working on large sample sizes in countries that can afford the cost. The Wantai ELISA, while requiring more individual time and technical skill, may provide reliable results at a lower cost. The selection of assays will depend on the laboratory facilities and feasibility.

Keywords: SARS-coronavirus-2, Antibody detection, Microneutralization assay, ELISA, Chemiluminescence assay

*Correspondence: pilaipan.put@mahidol.edu

'Center for Research and Innovation, Faculty of Medical Technology,

Mahidol University, Nakhon Pathom 73170, Thailand

Full list of author information is available at the end of the article

\section{Background}

Almost all immunocompetent individuals infected with severe acute respiratory syndrome coronavirus 2 (SARS$\mathrm{CoV}-2)$ develop antibodies specific to multiple viral 
proteins. In particular, antibodies to nucleoprotein $(\mathrm{N})$ and spike (S1 and S2) proteins are of clinical importance [1-4]. Specific IgM and IgA first appeared 7-14 days after the onset of disease symptoms, followed by IgG at approximately 14 days. IgM peaks at $2-5$ weeks and then declines a few weeks later, while IgG may persist longer [3, 5-8]. Anti-N antibodies developed before the anti-S antibodies $[9,10]$. Various immunological methods have demonstrated the binding activities of these immunoglobulin (Ig) isotypes, e.g., enzyme-linked immunosorbent assay (ELISA), chemiluminescence immunological assays (CLIAs), indirect immunofluorescence (IIF) assay, and immunochromatography. Additionally, plaque reduction neutralization (PRNT) or microNT assays detected functional or neutralizing (NT) antibodies. NT antibodies correlate with protective immunity, while binding antibodies may or may not [3, 8, 10-12]. Antibodies to the receptor-binding domain (RBD) in the $\mathrm{S} 1$ protein correlated well with NT antibody activity [2, 3, $10,12]$.

Antibody detection has served many purposes: supporting the diagnosis of SARS-CoV-2 infection when reverse transcription-polymerase chain reaction (RTPCR) for viral genomes yields an inconclusive result [3]; serosurveillance to estimate the cumulative incidence of SARS-CoV-2 infection [3, 13-15]; and vaccine evaluation, particularly by PRNT or microNT assays.

Currently, multiple commercial kits are available globally, and antigenic targets for these tests include the SARS-CoV-2 S, RBD, and N proteins [1-3]. Evaluations of most serological test kits used sera from RT-PCRconfirmed cases as the gold standard for comparison with COVID-19 prepandemic sera [16] or RT-PCR-negative sera [17]. Few studies have included assessments of SARS-CoV-2 binding antibodies against functional NT antibodies $[8,18]$. Many of these test kits require autoanalyzer machines that are expensive and inaccessible to laboratories in developing countries. Manual ELISAs of comparable performance may have broad utility in lower resource settings.

Therefore, we evaluated four serological assays that used different platforms against the microNT assay as the gold standard method for the detection of antiSARS-CoV-2 antibodies. The evaluation included two autoanalyzers using three chemiluminescence-based kits (Architech IgG, Vitros IgG, and Vitros total Ig) and a manual ELISA for total Ig (Beijing Wantai). We retested all samples with IIF to validate the discordant results of the microNT and the evaluated test kits. The test sera in this study included COVID-19 prepandemic sera, NT antibody-positive sera from SARS-CoV-2 infected cases, sera of persons at risk of SARS-CoV-2 infection, and sera of travellers returning from countries experiencing SARS-CoV-2 outbreaks at the time of this study.

\section{Methods \\ Ethical issues and the test sera}

This study was conducted following the Declaration of Helsinki and approved by the Mahidol University Central Institutional Review Board (MU-CIRB). The study comprised 1005 convenience serum samples from four groups of participants: (1) Archival COVID-19 prepandemic serum samples collected in 2019 before the emergence of SARS-CoV-2 as the negative controls $(\mathrm{N}=102)$. Participants provided informed consent for using their leftover sera in other research projects under the approval of the MU-CIRB protocol number MU-IRB 2017/180.1210; (2) Anonymized archival sera collected between 10 and 109 days after disease onset from cases with RT-PCR confirmed SARS-CoV-2 infection in 2020 as the positive controls $(\mathrm{N}=45)$. These sera were kindly provided by Rajvithi Hospital. MU-CIRB waived the requirement for informed consent because the sera were the leftover samples from a clinical laboratory investigation under the Protocol number MUCOVID2020.001/2503; (3) Serum samples collected in 2020 from 366 Thai people determined by the Ministry of Public Health (MoPH) to be at increased risk of infection (health personnel, taxi drivers, and workers in entertainment venues). The informed consent in this group of participants was also provided by the MU-CIRB protocol number MU-COVID2020.001/2503. In the enrolment process, survey staff explained the purpose of the study. Participants signed an informed consent form for the interview about demographics and occupational activities as well as the donation of approximately $5-8 \mathrm{ml}$ of blood using venipuncture. Blood specimens were labelled with study ID numbers. (4) Anonymous serum samples from 492 Thai citizens in state quarantines after returning to Thailand in 2020 from extended duty in countries with a known SARS-CoV-2 outbreak at the time of their return. These sera were sent from the Institute for Urban Disease Control and Prevention (IUDC), Department of Disease Control, $\mathrm{MoPH}$ for anti-SARS-CoV-2 antibody testing to support active case surveillance by RT-PCR. The outbreak investigation is considered a public health intervention; therefore, the Ethical Review Committee for Research related to COVID-19 Disease or Public Health Emergency, Department of Disease Control, MoPH (DDC ERC) exempted IRB approval and written informed consent due to its urgent nature. Nevertheless, participants received an explanation and gave verbal informed consent on specimen collection for laboratory diagnosis of SARS-CoV-2 infection. We included the 
laboratory results in our study analysis with permission from IUDC.

\section{Study design}

We evaluated the Wantai ELISA total Ig, Architect IgG, Vitros IgG, and Vitros total Ig tests against the microNT test as the reference assay. By its nature, microNT is less sensitive than binding antibody assay techniques. Therefore, IIF was used to retest specimens when the microNT and a commercial assay yielded discordant results. IIF may support the result of microNT or that of the commercial assay. The final result of a sample with discordant results followed that of the IIF assay.

\section{Microneutralization assay}

The present study conducted the microNT assay as described previously [19]. Vero cells (African green monkey kidney cells-ATCC, CCL-81) were grown in Eagle's minimum essential medium (EMEM) (Gibco, NY) supplemented with $10 \%$ fetal bovine serum (FBS) (Gibco, NY), antibiotics, and amphotericin B. SARSCoV-2 (hCoV-19/TH/MUMT-4/2020) was isolated and propagated in Vero cell cultures maintained in EMEM supplemented with $2 \%$ FBS. We calculated the virus concentration in the $50 \%$ tissue culture infective dose (TCID50) using the Reed-Muench method. We performed the experiments using the infectious viruses in a level 3 biosafety laboratory.

The cytopathic effect (CPE)-based microNT assay employed SARS-CoV-2 at a final concentration of 100 TCID50/100 $\mu \mathrm{l}$ and Vero cells grown in 96-well microculture plates in duplicate. The test serum was heatinactivated at $56{ }^{\circ} \mathrm{C}$ for $30 \mathrm{~min}$ and serially diluted twofold starting from an initial serum dilution of 1:10 up to $1: 1280$. Then, $60 \mu \mathrm{l}$ of each serum dilution was mixed with $60 \mu \mathrm{l}$ of the test virus (200 TCID50/100 $\mu \mathrm{l})$.
After incubation at $37{ }^{\circ} \mathrm{C}$ for $1 \mathrm{~h}, 100 \mu \mathrm{l}$ of the virus serum mixture was added into each well containing the Vero cell monolayer. The reaction plates were further incubated at $37^{\circ} \mathrm{C}$ and observed daily for 3 days before the results were obtained. The neutralizing antibody titer was the highest reciprocal serum dilution that inhibited $\geq 50 \% \mathrm{CPE}$ of the cell monolayer inoculated with the serum-virus mixture compared to the uninfected cultures.

\section{Indirect immunofluorescence assay}

Vero cell monolayers were infected with SARS-CoV-2 for 3-4 days and harvested when the infected cultures showed $50-75 \%$ CPE. The cells were scraped off the surface of the culture flask, suspended, washed, and spun. Then, the cell pellets were suspended, spotted onto microscopic glass slides, and air-dried before fixing in precooled acetone at $-20^{\circ} \mathrm{C}$ for $10 \mathrm{~min}$. The cell deposits were applied with rabbit monoclonal antibodies to SARS-CoV-2 N or spike S1 protein (Sino Biological, Beijing, China) and incubated at $37^{\circ} \mathrm{C}$ for $60 \mathrm{~min}$. After washing, goat anti-rabbit IgG $(\mathrm{H}+\mathrm{L})$-conjugated Alexa Fluor ${ }^{\circledR} 488$ (Invitrogen, Waltham, MA USA) was added, followed by the same staining procedure. The standard cell deposit contained approximately 50-75\% antigen-positive cells.

The staining for anti-SARS-CoV-2 antibodies in human sera employed a single serum dilution of 1:10 in a phosphate-buffered saline, and polyclonal rabbit antihuman IgA, IgG, IgM, Kappa, and Lambda conjugated with fluorescein isothiocyanate (Dako, Glostrup, Denmark) in Evans blue diluent were used as the secondary antibodies. The viral antigen localized in the cytoplasm of the infected cells appeared fluorescent apple green under a fluorescence microscope (Fig. 1).
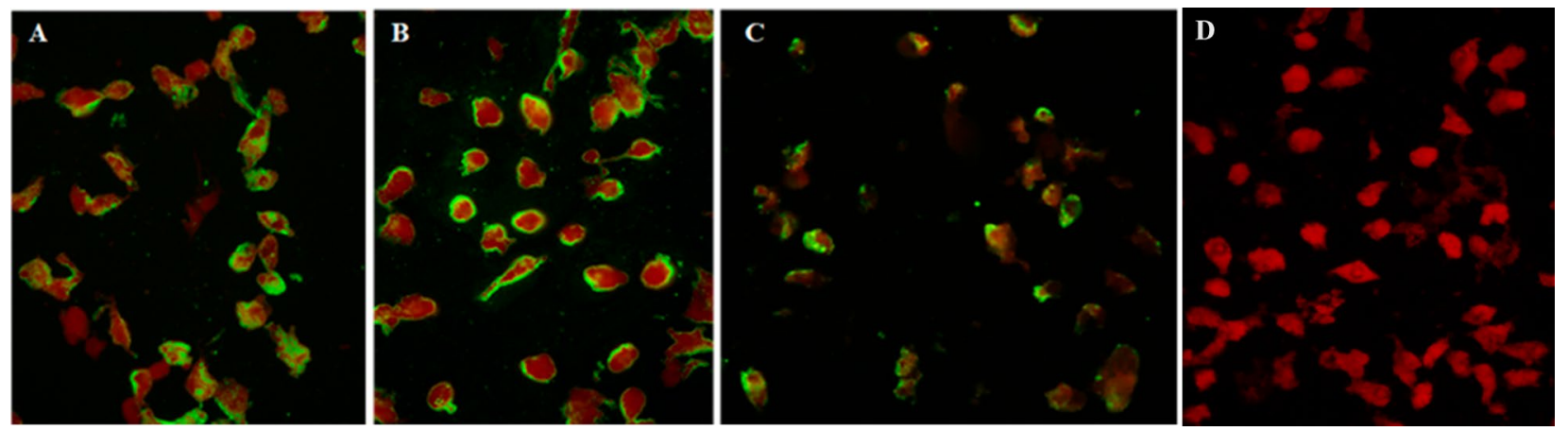

Fig. 1 Indirect immunofluorescence (IIF) assay of SARS-CoV-2-infected Vero cells stained with $\mathbf{A}$ monoclonal antibody to $S$ epitopes; B monoclonal antibody to $\mathrm{N}$ epitopes; and $\mathbf{C}$ human serum at a dilution of 1:10. This serum sample was negative by microNT but positive by Wantai ELISA, Vitros total Ig, and IIF; and $\mathbf{D}$ human negative serum control. The fluorescent positive cells appeared apple green in the cytoplasm of the infected cells 


\section{Wantai ELISA for SARS-CoV-2 total Ig}

Sandwich ELISA (Wantai Biological Pharmacy, Beijing, China) for detecting anti-SARS-CoV-2 total antibodies was determined using a plate precoated with the RBD of the SARS-CoV-2 spike protein. The reaction consisted of two steps. First, $100 \mu \mathrm{l}$ of the serum was incubated with the RBD at $37{ }^{\circ} \mathrm{C}$ for 30 min before washing. Second, horseradish peroxidase (HRP)-conjugated RBD was added to each reaction well and further incubated at $37{ }^{\circ} \mathrm{C}$ for $30 \mathrm{~min}$ before washing and adding a chromogenic solution for $15 \mathrm{~min}$. The amount of the SARSCoV-2 antibodies was proportional to the optical density values as measured under a spectrophotometer using dual wavelengths of $450 \mathrm{~nm}$ and $630 \mathrm{~nm}$. The absorbance value $(\mathrm{A})$ of the test sample was divided by the cutoff value (C.O.) to determine the A/C.O. ratio. Ratios of $\geq 1$ were considered positive for SARS-CoV-2 antibodies, and ratios between 0.9 and 1.1 were considered borderline and retested.

\section{Architect SARS-CoV-2 IgG}

We used an Architect autoanalyzer (Abbott Laboratories, Inc., USA) to semiquantitatively detect anti-SARS-CoV-2 IgG. The assay is a two-step immunoassay that involves binding between the SARS-CoV-2N antigen coated on the paramagnetic microparticles and human IgG in the test sera, followed by acridinium-conjugated anti-human IgG as the secondary antibody. The chemiluminescence signals emitted were measured as relative light units (RLUs), which correlated with the amount of the specific IgG. The RLU of the sample (S) divided by the calibrator $(C)$ yielded the index $S / C$ ratio. Test sera with $S / C$ ratios $\geq 1.4$ were considered positive for SARS-CoV-2 IgG.

\section{Vitros immunodiagnostics}

The Vitros Immunodiagnostics autoanalyzer (OrthoClinical Diagnostics, Inc., U.S.A.) is a two-step immunoassay for semiquantitatively detecting anti-SARS-CoV-2 IgG or total Ig. The use of a luminogenic substrate and an electron transfer reagent that increased the emitted light level enhanced the chemiluminescence. The S1 protein precoated on the microwells reacted with human IgG or total Ig, which subsequently reacted with either HRPconjugated mouse anti-human IgG or anti-total Ig. The intensity of the emitted light correlated with the amount of IgG binding or the total Ig in the test sera. Values of $\geq 1$ were considered positive for both SARS-CoV-2 IgG and total Ig.

\section{Statistical analysis}

We determined the sensitivity, specificity, positive predictive value (PPV), and negative predictive value (NPV) of each serological assay using all 1005 serum samples as a whole and in certain subgroups, as appropriate. The study also determined the correlations between the index values of each assay and the NT antibody titer to assess whether the index levels correlated with the protective antibodies. We performed all analyses using the Stata program, version 16 . $R$ square $\left(R^{2}\right)$, mean, and standard deviation (SD) were analysed by GraphPad Prism version 8.4.3 for Windows (GraphPad Software, La Jolla, California, USA). The figures were drawn using GraphPad Prism version 8.4.3 for Windows (GraphPad).

\section{Results}

Evaluation of test performance using negative control sera When run on the 102 COVID-19 prepandemic negativecontrol sera, all assays (microNT, Wantai ELISA total Ig, Architect IgG, Vitros IgG, and Vitros total Ig) yielded negative results, except one sample that was positive by the Vitros total Ig. Retesting of the one discordant result with IIF suggested that this sample was negative for SARS-CoV-2 antibodies.

\section{Evaluation of test performance using positive control sera}

When tested on the 45 microNT antibody-positive serum samples from SARS-CoV-2-infected cases, the Wantai ELISA and Vitros total Ig detected SARS-CoV-2 antibodies in all serum samples (sensitivity $=100 \%$ ) (45/45). Architect IgG and Vitros IgG had sensitivities of $88.9 \%(40 / 45)$ and $82.2 \%(37 / 45)$, respectively. We used IIF to retest the 13 problem serum samples and found that all were positive, indicating SARS-CoV-2 infection.

\section{Evaluation of test performance using sera of persons from the general community}

Among the sera collected from the 366 individuals investigated as being at risk of SARS-CoV-2 infection in 2020, only two sera $(0.55 \%)$ were true positives (Table 1$)$, suggesting a low prevalence of infection in this population at the time of the study. Architect IgG was the only kit that did not detect either of the two positive serum samples. All other assays detected both positive specimens, showing a sensitivity of $100 \%$. The specificity and NPV of these assays were also all above $99 \%$. Nevertheless, based on IIF verification, each assay produced between one and three false-positive results, leading to PPVs of $40 \%$ with Wantai ELISA, 50\% with Vitros IgG, 66.7\% with Vitros total Ig, and $100 \%$ with microNT (Table 1 ).

\section{Evaluation of test performance using sera of returning travellers from countries with a high prevalence of infection}

Of the 492 serum samples from Thai citizens returning from foreign countries, $139(28.3 \%)$ were positive for 
Table 1 Test performance of each serological assay among persons investigated as being at risk of SARS-CoV-2 infection in the general population $(\mathrm{N}=366)$

\begin{tabular}{|c|c|c|c|c|c|c|c|}
\hline \multirow[t]{2}{*}{ Assays } & \multicolumn{2}{|c|}{ MicroNT } & \multirow[t]{2}{*}{$\begin{array}{l}\text { Number positive IIF among } \\
\text { discordant results }\end{array}$} & \multicolumn{4}{|l|}{$\begin{array}{l}\% \\
(95 \% \mathrm{Cl})\end{array}$} \\
\hline & Pos & Neg & & Sens & Spec & PPV & NPV \\
\hline MicroNT & 2 & 364 & & 100 & 100 & 100 & 100 \\
\hline \multicolumn{8}{|c|}{ Wantai total lg } \\
\hline Pos & 2 & 3 & 0 of 3 & 100 & 99.2 & 40.0 & 100 \\
\hline Neg & 0 & 361 & & $(15.8,100)$ & $(97.6,99.8)$ & $(5.3,85.3)$ & $(99.0,100)$ \\
\hline \multicolumn{8}{|c|}{ Architect lgG } \\
\hline Pos & 0 & 3 & 2 of 5 & 0 & 99.2 & 0 & 99.5 \\
\hline Neg & 2 & 361 & & $(0,84.2)$ & $(97.6,99.8)$ & $(0,70.8)$ & $(98.0,99.9)$ \\
\hline \multicolumn{8}{|l|}{ Vitros lgG } \\
\hline Pos & 2 & 2 & 0 of 2 & 100 & 99.5 & 50.0 & 100 \\
\hline Neg & 0 & 362 & & $(15.8,100)$ & $(98.0,99.9)$ & $(6.8,93.2)$ & $(99.0,100)$ \\
\hline \multicolumn{8}{|c|}{ Vitros total Ig } \\
\hline Pos & 2 & 1 & 0 of 1 & 100 & 99.7 & 66.7 & 100 \\
\hline Neg & 0 & 363 & & $(15.8,100)$ & $(98.5,100)$ & $(9.4,99.2)$ & $(99.0,100)$ \\
\hline
\end{tabular}

Final results after IIF verification: $\mathrm{Pos}=2, \mathrm{Neg}=364$

Pos positive, Neg negative, Sens sensitivity, Spec specificity, PPV positive predictive value, NPV negative predictive value, $95 \%$ CI $95 \%$ confidence interval

SARS-CoV-2 antibodies. In this higher prevalence population, the sensitivity of the assays ranged from 89.9 to $100 \%$, and the specificities were all above $98.9 \%$. The PPV and NPV of the assays were all over $97.2 \%$ and $96.2 \%$, respectively, as shown in Table 2. A single serum sample tested negative by microNT, whereas it tested positive by the Wantai ELISA, Vitros total Ig, and IIF. The fluorescent-positive cells are shown in Fig. 1.

\section{Evaluation of sera in the overall combined samples}

Of the 1005 sera in the combined sample sets, 186 (18.5\%) were positive for SARS-CoV-2 antibodies. The microNT and the other four commercial kits yielded discordant results in 55 serum samples, and IIF retested them. All the microNT results, either positive or negative, were supported by IIF. An exception occurred with one sample, which was positive by Wantai ELISA and Vitros total Ig but negative by microNT, resulting in a

Table 2 Test performance of each serological assay in travellers returning from higher prevalence locations $(\mathrm{N}=492)$

\begin{tabular}{|c|c|c|c|c|c|c|c|}
\hline \multirow[t]{2}{*}{ Assays } & \multicolumn{2}{|c|}{ MicroNT } & \multirow[t]{2}{*}{$\begin{array}{l}\text { Number positive IIF among the } \\
\text { discordant results }\end{array}$} & \multicolumn{4}{|l|}{$\begin{array}{l}\% \\
(95 \% \mathrm{Cl})\end{array}$} \\
\hline & Pos & Neg & & Sens & Spec & PPV & NPV \\
\hline MicroNT & 138 & 354 & & 99.3 & 100 & 100 & 99.7 \\
\hline \multicolumn{8}{|c|}{ Wantai total lg } \\
\hline Pos & 138 & 5 & 1 of 5 & 100 & 98.9 & 97.2 & 100 \\
\hline Neg & 0 & 349 & & $(97.4,100)$ & $(97.1,99.7)$ & $(93.0,99.2)$ & $(99.0,100)$ \\
\hline \multicolumn{8}{|c|}{ Architect IgG } \\
\hline Pos & 126 & 2 & 12 of 14 & 90.7 & 99.4 & 98.4 & 96.4 \\
\hline Neg & 12 & 352 & & $(84.5,95.0)$ & $(98.0,99.9)$ & $(94.5,99.8)$ & $(94.0,98.1)$ \\
\hline \multicolumn{8}{|l|}{ Vitros IgG } \\
\hline Pos & 137 & 4 & 1 of 5 & 98.7 & 98.9 & 97.2 & 99.4 \\
\hline Neg & 1 & 350 & & $(94.9,99.8)$ & $(97.1,99.7)$ & $(92.9,99.2)$ & $(98.0,99.9)$ \\
\hline \multicolumn{8}{|c|}{ Vitros total lg } \\
\hline Pos & 124 & 2 & 15 of 16 & 89.9 & 99.7 & 99.2 & 96.2 \\
\hline Neg & 14 & 352 & & $(83.7,94.4)$ & $(98.4,100)$ & $(95.7,100)$ & $(93.7,97.9)$ \\
\hline
\end{tabular}


sensitivity of $99.5 \%$, NPV of $99.9 \%$, and specificity and PPV of $100 \%$. The Wantai ELISA total Ig had the highest sensitivity (100\%) and was followed in order by microNT (99.5\%), Vitros IgG (94.6\%), Vitros total Ig (92.5\%), and Architect IgG (89.3\%). The specificities of all commercial kits were over 99\%; the PPVs and NPVs were over 96\% and $97 \%$, respectively (Table 3 ).

\section{Correlation between the NT antibody titers and the positive values of each assay}

This study determined the correlations between the NT antibody titers and the index values obtained from each commercial assay. The results in Fig. 2 demonstrate a moderate degree of correlation between the microNT assay and the Architect IgG assay, which employed the $\mathrm{N}$ antigen $\left(\mathrm{R}^{2}=0.7781\right)$, and between the microNT assay and the Wantai ELISA total Ig, which employed the RBD antigen $\left(R^{2}=0.7763\right)$. NT antibody titers poorly correlated with the positive values of both Vitros total Ig and Vitros IgG, which employed the S1 antigen $\left(R^{2}=0.2987\right.$ and 0.3149 , respectively).

\section{Discussion}

In Thailand, commercial antibody testing assays must receive approval from the Food and Drug Administration (FDA) based on having a diagnostic sensitivity of $\geq 85 \%$, diagnostic specificity of $\geq 98 \%$, and nonspecificity or cross-reactivity of $\leq 10 \%$, as evaluated using a serum panel from the National Institute of Health, Department of Medical Science, MoPH. The Architect IgG, Vitros IgG, and Vitros total Ig assays have been certified for use and marketing in Thailand. The Wantai ELISA total Ig has been CE (Conformite Europeene) approved for usage in the European Union, but the company has not yet submitted a proposal for its distribution in Thailand. However, Thailand participates in the World Health Organization (WHO) population-based, age-stratified seroepidemiological UNITY study. The study aims to promote standardized epidemiological, molecular, and serological methods to facilitate international comparisons and inform decisions for the COVID-19 response [20], and the WHO offered Wantai ELISA kits to Thailand for this purpose. As a result, Mahidol University received an exemption from the Thai FDA to import these ELISA kits, allowing its inclusion in this evaluation.

The present study evaluated Wantai ELISA total Ig, Architect IgG, Vitros IgG, and Vitros total Ig test kits against microNT (supplemented with IIF verification) in detecting SARS-CoV-2 antibodies. Analysis of sera from 1005 Thai citizens showed that the four serological assays evaluated were relatively comparable in terms of sensitivity (89.3-100\%), specificity (99.2-100\%), PPV (96.4-100\%), and NPV (97.6-100\%). While all assays performed well in this evaluation, the analyses stratified by subgroups provided additional insights. As might be expected, the performance of these serological assays diminished when the prevalence of the infection was low, as in the group of 366 Thai community members, among whom only two were positive. In this group, the assays either suffered from a low sensitivity (Architect IgG) or correctly identified the positive sera but produced varying false-positive results (Wantai total Ig, Vitros total Ig, and Vitros IgG). Previous studies have also reported the reduced performance of serological assays when the

Table 3 Test performance of each serological assay in the overall study $(N=1005)$

\begin{tabular}{|c|c|c|c|c|c|c|c|}
\hline \multirow[t]{2}{*}{ Assays } & \multicolumn{2}{|c|}{ MicroNT } & \multirow[t]{2}{*}{$\begin{array}{l}\text { Number positive IIF among } \\
\text { discordant results }\end{array}$} & \multicolumn{4}{|l|}{$\begin{array}{l}\% \\
(95 \% \mathrm{Cl})\end{array}$} \\
\hline & Pos & Neg & & Sens & Spec & PPV & NPV \\
\hline MicroNT & 185 & 820 & & 99.5 & 100 & 100 & 99.9 \\
\hline \multicolumn{8}{|c|}{ Wantai total lg } \\
\hline Pos & 185 & 8 & 1 of 8 & 100 & 99.2 & 96.4 & 100 \\
\hline Neg & 0 & 812 & & $(98.0,100)$ & $(98.3,99.7)$ & $(92.7,98.5)$ & $(99.6,100)$ \\
\hline \multicolumn{8}{|c|}{ Architect lgG } \\
\hline Pos & 166 & 5 & 19 of 24 & 89.3 & 99.4 & 97.1 & 97.6 \\
\hline Neg & 19 & 815 & & $(83.9,93.3)$ & $(98.6,99.8)$ & $(93.3,99.0)$ & $(96.3,98.5)$ \\
\hline \multicolumn{8}{|l|}{ Vitros IgG } \\
\hline Pos & 176 & 6 & 9 of 15 & 94.6 & 99.3 & 96.7 & 98.8 \\
\hline Neg & 9 & 814 & & $(90.3,97.4)$ & $(98.4,99.7)$ & $(93.0,98.8)$ & $(97.8,99.4)$ \\
\hline \multicolumn{8}{|c|}{ Vitros total Ig } \\
\hline Pos & 171 & 4 & 15 of 18 & 92.5 & 99.6 & 98.3 & 98.3 \\
\hline Neg & 14 & 816 & & $(87.7,95.8)$ & $(98.9,99.9)$ & $(95.1,99.7)$ & $(97.2,99.1)$ \\
\hline
\end{tabular}

Final results after IIF verification: $\mathrm{Pos}=186, \mathrm{Neg}=819$ 

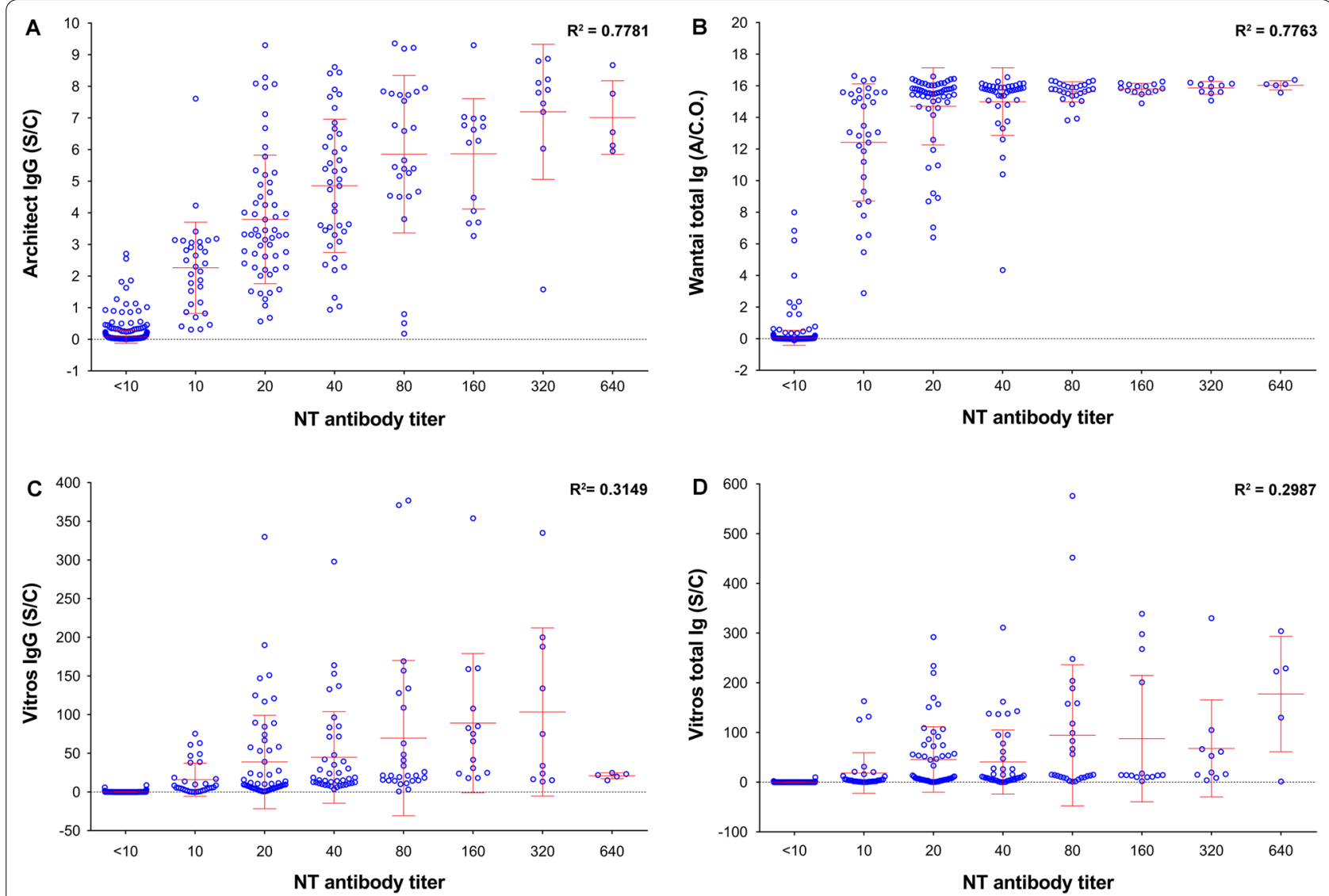

Fig. 2 Correlation between the microNT antibody titers and the index values of each commercial assay: A Architect lgG; B Wantai ELISA total Ig assay; C Vitros IgG; and D Vitros total Ig. R square $\left(R^{2}\right)$, mean (-), and SD were analysed by GraphPad Prism version 8.4.3 for Windows (GraphPad Software, La Jolla, California, USA)

infection rates were low, which significantly impacted PPV values [21-23]. According to the orthogonal testing algorithm, individuals who were initially positive by the first-line assay required retesting with a second-line assay for confirmation $[24,25]$. The commercial assays used in this study did not yield false-positive results when evaluated with COVID-19 prepandemic sera (except a single serum sample investigated by Vitros total Ig).

This study sought to determine the correlation between the NT antibody titers and the index values of results from each commercial assay. The S/C ratios of Architect IgG correlated well with the NT antibody titers $\left(R^{2}=0.778\right)$. This correlation was unexpected because Architect IgG targets the $\mathrm{N}$ antigen, which contains no neutralizing epitopes. This finding suggested that both microNT and Architect IgG which target different antigenic domains, can yield comparable results on the detection of previous infection. On the other hand, the NT antibody titers also correlated well with the A/C.O. values of Wantai ELISA total Ig, which targets the RBD $\left(R^{2}=0.776\right)$, the primary neutralizing domain [2].
Previous investigators demonstrated that Wantai ELISA total Ig had the highest sensitivity compared to the other four commercial serological tests (BIORAD ${ }^{\circledR}$ ELISA total Ig, EUROIMMUN ${ }^{\circledR}$ ELISA IgG, Abbott ${ }^{\circledR}$ CLIA IgG, and LIAISON $^{\circledR}$ CLIA IgG) when assayed in serum samples from nonhospitalized, laboratory-confirmed SARSCoV-2 infection [26]. After 14 days postsymptom onset, Wantai ELISA total Ig had 98\% agreement with microNT [22]. Other investigators also suggested that the Wantai ELISA could be a suitable substitute for the microNT assay [18]. Our study found that the NT antibody titers correlated poorly with the index values of Vitros total Ig $\left(R^{2}=0.2987\right)$ and Vitros IgG $\left(R^{2}=0.3149\right)$, which target the S1 protein. We do not have a clear explanation for this finding, as the S1 protein contains multiple antigenic sites in both the RBD and non-RBD that can induce NT antibodies [2, 27-29]. Nevertheless, chemiluminescent signals set by Vitros kits were adequate to report the positive or negative results as designed by the manufacturer. Poor correlation between the level of chemiluminescent signals and neutralizing antibodies did not affect the kit 
quality, because the sensitivities of both Vitros IgG and total Ig were slightly higher than Architect IgG, whereas the specificities were comparable.

In virology laboratories worldwide, microNT is the "gold standard" method for evaluating other antibody assay systems because of its high specificity. MicroNT may not always detect an early infection, as it takes time for antibodies to rise to a level that can neutralize the replicating virus at a concentration of 100 TCID50. Furthermore, some infected individuals may develop a moderate level of binding antibodies without NT antibodies. It is thus possible that serological assays that measure binding antibody activities might be more sensitive than microNT, particularly in the early phase of infection. The advantage of our study was the introduction of IIF (in which the test cells contained both $\mathrm{N}$ and $\mathrm{S}$ antigens) to verify any discordant results between microNT and a binding antibody assay. We showed that the microNT assay missed one positive sample, which the Wantai ELISA and Vitros total Ig could determine with IIF verification.

\section{Conclusions}

Our study found that several commercial serological assays performed well for semiqualitatively determining the presence of anti-SARS-CoV-2 antibodies. However, in low prevalence populations, they may also produce falsepositive results. High-throughput Architect and Vitros autoanalyzers may be the most appropriate for working on large sample sizes in countries that can afford the costs. The Wantai manual ELISA, while requiring more individual time and technical skill, may provide reliable results at a lower price. As the COVID-19 pandemic progresses, our findings can aid in selecting an appropriate serological assay for antibody detection to diagnose a past SARS-CoV-2 infection and estimate infection rates or the magnitude of the outbreaks. The assay of choice will ultimately depend on the study population, laboratory facilities, and feasibility.

\section{Abbreviations \\ microNT: Microneutralization; SARS-CoV-2: Severe acute respiratory syndrome- coronavirus-2; COVID-19: Coronavirus disease 2019; ELISA: Enzyme-linked immunosorbent assay; CLIAs: Chemiluminescence immunological assays; IIF: Indirect immunofluorescence; PRNT: Plaque reduction neutralization; RBD: Receptor-binding domain; TCID50: 50\% Tissue culture infective dose; PPV: Positive predictive value; NPV: Negative predictive value.}

\section{Acknowledgements}

We thank Abbott Laboratories Inc. and the Ortho-Diagnostics for donating their products and the World Health Organization for donating the Wantai ELISA kits to this study. We are grateful to the Department of Disease Control for facilitating the field investigation. We thank Chinda Kanoksinsombat for coordinating the project. We thankTipsuda Chanmanee, Worawat Dangsakul, Anusara Jitsatja, Rumporn Kularb, Domrongrit Taonan, and Phanupong
Nutthabat for their laboratory assistance. We also thank Dr. Arthur Brown for English editing.

\section{Authors' contributions}

HL performed experiments, analyzed and interpreted data, drafted the manuscript. AM, and SI facilitated the field studies and provided resources. PI, and NS provided samples. JP, NT, and SP performed experiments. SSa performed experiments and data analyses. KP, SSi, and NM assisted in the field investigation and specimen collection. WW supported the BSL-3 laboratory facilities. PP, the grant principal investigator, conceptualized and designed the study, supervised the laboratory work and data analysis, drafted, edited, and finalized the manuscript. All authors read and approved the final manuscript.

\section{Funding}

This study received financial support from the National Research Council of Thailand (NRCT) Grant No. NRCT 11/2563 and the National Science and Technology Development Grant No. P-17-50551.

\section{Availability of data and materials}

The datasets used and/or analyzed during the current study are available from the corresponding author on reasonable request.

\section{Declarations}

\section{Ethics approval and consent to participate}

The Mahidol University Central Institutional Review Board (MU-CIRB) approved this study under the protocol numbers MU-IRB 2017/180.1210 for the study sera in group 1, and MU-COVID2020.001/2503 for the study sera in groups 2 and 3 . Regarding the study sera in group 4, the Institute for Urban Disease Control and Prevention (IUDC), Department of Disease Control, MoPH got an exemption from the Ethical Review Committee for Research related to COVID19 Disease or Public Health Emergency, Department of Disease Control, Ministry of Public Health (DDC ERC) for IRB approval and written informed consent on the outbreak investigation and a public health intervention due to its emergency nature. Nevertheless, participants gave verbal informed consent on specimen collection for laboratory diagnosis of SARS-CoV-2 infection.

\section{Consent for publication}

Not applicable.

\section{Competing interests}

The authors declare no competing interests.

\section{Author details}

${ }^{1}$ Center for Research and Innovation, Faculty of Medical Technology, Mahidol University, Nakhon Pathom 73170, Thailand. Institute for Urban Disease Control and Prevention, Department of Disease Control, Ministry of Public Health, Bangkok 10220, Thailand. ${ }^{3}$ Department of Disease Control, Ministry of Public Health, Nonthaburi 11000, Thailand. ${ }^{4}$ Department of Medical Services, Nakhon Phanom Provincial Hospital, Ministry of Public Health, Nakhon Phanom 48000, Thailand. ${ }^{5}$ Division of Infectious Disease, Department of Medicine, Rajavithi Hospital, Ministry of Public Health, Bangkok 10400, Thailand. ${ }^{6}$ Faculty of Veterinary Science, Mahidol University, Nakhon Pathom 73170, Thailand.

Received: 19 June 2021 Accepted: 29 November 2021

Published online: 06 December 2021

References

1. Zeng W, Liu G, Ma H, Zhao D, Yang Y, Liu M, et al. Biochemical characterization of SARS-CoV-2 nucleocapsid protein. Biochem Biophys Res Commun. 2020;527(3):618-23. https://doi.org/10.1016/j.bbrc.2020.04.136.

2. Premkumar L, Segovia-Chumbez B, Jadi R, Martinez DR, Raut R, Markmann $A$, et al. The receptor-binding domain of the viral spike protein is an immunodominant and highly specific target of antibodies in SARS-CoV-2 patients. Sci Immunol. 2020;5(48):eabc8413. https://doi.org/10.1126/ sciimmunol.abc8413.

3. Centers for Disease Control and Prevention. Interim guidelines for COVID19 antibody testing in clinical and public health settings. 2021. https:// 
www.cdc.gov/coronavirus/2019-ncov/lab/resources/antibody-testsguidelines.html. Updated 17 Mar 2021. Accessed 15 June 2021.

4. Bohn MK, Loh TP, Wang C-B, Mueller R, Koch D, Sethi S, et al. IFCC Interim guidelines on serological testing of antibodies against SARS-CoV-2. Clin Chem Lab Med. 2020;58(12):2001-8. https://doi.org/10.1515/ cclm-2020-1413.

5. Sethuraman N, Jeremiah SS, Ryo A. Interpreting diagnostic tests for SARSCoV-2. JAMA. 2020;323(22):2249-51. https://doi.org/10.1001/jama.2020. 8259.

6. Guo L, Ren L, Yang S, Xiao M, Chang D, Yang F, et al. Profiling early humoral response to diagnose novel coronavirus disease (COVID-19). Clin Infect Dis. 2020;71(15):778-85. https://doi.org/10.1093/cid/ciaa310.

7. Post N, Eddy D, Huntley C, van Schalkwyk MCl, Shrotri M, Leeman D, et al. Antibody response to SARS-CoV-2 infection in humans: a systematic review. PLoS ONE. 2020;15(12):e0244126. https://doi.org/10.1371/journal. pone.0244126.

8. Wu J, Liang B, Chen C, Wang H, Fang Y, Shen S, et al. SARS-CoV-2 infection induces sustained humoral immune responses in convalescent patients following symptomatic COVID-19. Nat Commun. 2021;12(1):1813. https:// doi.org/10.1038/s41467-021-22034-1.

9. Burbelo PD, Riedo FX, Morishima C, Rawlings S, Smith D, Das S, et al. Sensitivity in detection of antibodies to nucleocapsid and spike proteins of severe acute respiratory syndrome coronavirus 2 in patients with coronavirus disease 2019. J Infect Dis. 2020;222(2):206-13. https://doi.org/10. 1093/infdis/jiaa273.

10. GeurtsvanKessel $\mathrm{CH}$, Okba NMA, Igloi Z, Bogers S, Embregts CWE, Laksono BM, et al. An evaluation of COVID-19 serological assays informs future diagnostics and exposure assessment. Nat Commun. 2020;11(1):3436. https://doi.org/10.1038/s41467-020-17317-y.

11. Walker GJ, Naing Z, Stella AO, Yeang M, Caguicla J, Ramachandran V, et al. SARS coronavirus-2 microneutralisation and commercial serological assays correlated closely for some but not all enzyme immunoassays. Viruses. 2021;13(2):247. https://doi.org/10.3390/v13020247.

12. Riepler L, Rössler A, Falch A, Volland A, Borena W, von Laer D, et al. Comparison of four SARS-CoV-2 neutralization assays. Vaccines (Basel). 2020;9(1):13. https://doi.org/10.3390/vaccines9010013.

13. Xu X, Sun J, Nie S, Li H, Kong Y, Liang M, et al. Seroprevalence of immunoglobulin $\mathrm{M}$ and $\mathrm{G}$ antibodies against SARS-CoV-2 in China. Nat Med. 2020;26(8):1193-5. https://doi.org/10.1038/s41591-020-0949-6.

14. Stadlbauer D, Tan J, Jiang K, Hernandez MM, Fabre S, Amanat F, et al. Repeated cross-sectional sero-monitoring of SARS-CoV-2 in New York City. Nature. 2021;590(7844):146-50. https://doi.org/10.1038/ s41586-020-2912-6.

15. Gudbjartsson DF, Norddahl GL, Melsted P, Gunnarsdottir K, Holm H, Eythorsson E, et al. Humoral immune response to SARS-CoV-2 in Iceland. N Engl J Med. 2020;383(18):1724-34. https://doi.org/10.1056/NEJMo a2026116.

16. The National SARS-CoV-2 Serology Assay Evaluation Group. Performance characteristics of five immunoassays for SARS-CoV-2: a head-to-head benchmark comparison. Lancet Infect Dis. 2020;20(12):1390-400. https:// doi.org/10.1016/S1473-3099(20)30634-4.

17. Krüttgena A, Cornelissenb CG, Dreher M, Hornef M, Imöhla M, Kleinesa M. Comparison of four new commercial serologic assays for determination of SARS-CoV-2 lgG. J Clin Virol. 2020;128:104394. https://doi.org/10.1016/j. jcv.2020.104394.

18. Weidner L, Gänsdorfer S, Unterweger S, Weseslindtner L, Drexler C, Farcet $M$, et al. Quantification of SARS-CoV-2 antibodies with eight commercially available immunoassays. J Clin Virol. 2020;129:104540. https://doi.org/10. 1016/j.jcv.2020.104540.

19. Lerdsamran H, Prasertsopon J, Mungomklang A, Klinmalai C, Noisamdaeng P, Sangsiriwut K, et al. Seroprevalence of antibodies to enterovirus 71 and coxsackievirus A16 among people of various age groups in a northeast province of Thailand. Virol J. 2018;15(1):158. https://doi.org/10. 1186/s12985-018-1074-8.

20. World Health Organization. The Unity Studies: WHO sero-epidemiological investigations protocols. 2021. https://www.who.int/emergencies/disea ses/novel-coronavirus-2019/technical-guidance/early-investigations\#: : text=The\%20Unity\%20Studies\%3A\%20WHO\%20Sero,evidence $\% 2$ Dbas ed\%20knowledge\%20for\%20action.\&text=generic\%20epidemiological\% 20investigation\%20protocols\%20branded\%20as\%20UNITY\%20studies. Accessed 19 June 2021.
21. Oved K, Olmer L, Shemer-Avni Y, WolfT, Supino-Rosin L, Prajgrod G, et al. Multi-center nationwide comparison of seven serology assays reveals a SARS-CoV-2 non-responding seronegative subpopulation. EClinicalMedicine. 2020;29:100651. https://doi.org/10.1016/j.eclinm.2020.100651.

22. Nicholson S, Karapanagiotidis T, Khvorov A, Douros C, Mordant F, Bond K, et al. Evaluation of 6 commercial SARS-CoV-2 serology assays detecting different antibodies for clinical testing and serosurveillance. Open Forum Infect Dis. 2021;8(7):ofab239. https://doi.org/10.1093/ofid/ofab239.

23. Bond K, Nicholson S, Lim SM, Karapanagiotidis T, Williams E, Johnson D, et al. Evaluation of serological tests for SARS-CoV-2: implications for serology testing in a low-prevalence setting. J Infect Dis. 2020;222(8):1280-8. https://doi.org/10.1093/infdis/jiaa467.

24. Xu G, Emanuel AJ, Nadig S, Mehrotra S, Caddell BA, Curry SR, et al. Evaluation of orthogonal testing algorithm for detection of SARS-CoV-2 lgG antibodies. Clin Chem. 2020. https://doi.org/10.1093/clinchem/hvaa210.

25. Centers for Disease Control and Prevention. Interim guidelines for COVID19 antibody testing in clinical and public health settings. 2020. https:// www.hsdl.org/?view\&did=838930. Updated 1 Aug 2020. Accessed 19 Jun 2021.

26. Brochot E, Demey B, Handala L, François C, Duverlie G, Castelain S, et al. Comparison of different serological assays for SARS-CoV-2 in real life. J Clin Virol. 2020;130:104569. https://doi.org/10.1016/j.jcv.2020.104569.

27. Brouwer PJM, Caniels TG, van der Straten K, Snitselaar JL, Aldon Y, Bangaru $\mathrm{S}$, et al. Potent neutralizing antibodies from COVID-19 patients define multiple targets of vulnerability. Science. 2020;369(6504):643-50. https:// doi.org/10.1126/science.abc5902.

28. Chi X, Yan R, Zhang J, Zhang G, Zhang Y, Hao M, et al. A neutralizing human antibody binds to the $\mathrm{N}$-terminal domain of the spike protein of SARS-CoV-2. Science. 2020;369(6504):650-5. https://doi.org/10.1126/ science.abc6952.

29. Keng CT, Zhang A, Shen S, Lip KM, Fielding BC, Tan THP, et al. Amino acids 1055 to 1192 in the S2 region of severe acute respiratory syndrome coronavirus $\mathrm{S}$ protein induce neutralizing antibodies: implications for the development of vaccines and antiviral agents. J Virol. 2005;79(6):3289-96. https://doi.org/10.1128/JVI.79.6.3289-3296.2005.

\section{Publisher's Note}

Springer Nature remains neutral with regard to jurisdictional claims in published maps and institutional affiliations.

Ready to submit your research? Choose BMC and benefit from:

- fast, convenient online submission

- thorough peer review by experienced researchers in your field

- rapid publication on acceptance

- support for research data, including large and complex data types

- gold Open Access which fosters wider collaboration and increased citations

- maximum visibility for your research: over $100 \mathrm{M}$ website views per year

At BMC, research is always in progress.

Learn more biomedcentral.com/submissions 